\title{
THE BLACK SWAN IN MANAGEMENT STRATEGY
}

\author{
DINU Laurențiu-George ${ }^{1}$ \\ Valahia University, IOSUD, Târgoviște, Romania, dinulaur2005@gmail.com
}

\begin{abstract}
The present study refers to the identification of priorities for managers in several small companies in Romania, in the current context. All of them have trade as their main activity, they have a small turnover, leading us to the so-called family business. The analyzed period is between September 2020 and January 2021, a period influenced by certain factors, such as: Romania was on „alert" throughout all the country, there were certain restrictions, schools were held online, there were holidays winter, parliamentary elections that took place, it was the cold season too and the vaccination campaign began on December 26, 2020.
\end{abstract}

KEY WORDS: management strategies, black swan, COVID-19

\section{INTRODUCTION}

The ,black swan" term comes from a Latin expression written by the poet Juvenal. Thus, he says that „rare avis in terris nigroque simillima cygno" (a good man is as rare as a black swan). The term was introduced in English, at a time when there were supposed to be no black swans. The importance of metaphor is given by the analogy to the fragility of any system of thinking. A set of conclusions can be cancelled in any moment when its fundamental postulates is invalidated. In this case, the appearance of a single black swan, invalidates both the logic of the phrase „All swans are white” and any other deductions based on it.

Juvenal's phrase was a common expression in sixteenth-century, in London, being used as an emphasis on the impossibility of a fact. The English expression comes from the Old-World assumption that all swans must be white, since all historical records speak exclusively of white swans. In such a context, the notion of the black swan was impossible, or, at best, nonexistent. After the Dutch explorer Willem de Vlamingh discovered black swans in Western Australia in 1697, the term began to be used to define an impossible thing that could become possible later (Montanari, J., 1989). In the 19th century, John Stuart Mill used the black swan logic error as a new term for identifying fake.

The theory of „Black Swan” type events proposed by Nassim Nicholas Taleb, is a metaphor used to describe an unexpected event that has a major impact and is streamlined retrospectively. The theory serves to explain (Taleb, N., 2016):

$\square \quad$ the disproportionate role of rare events, with major impact and difficult to predict, that exceed the limits of normal expectations in history, science, economics and technology;

the impossibility of calculating the probability of rare events with the help of scientific methods;

psychological prejudices, individual and collective, which make us indifferent to the uncertainty and the massive role of rare historical events.

What is now called the „Black Swan" is an event that has the following three attributes:

$\square \quad$ it is an extreme, it is outside the normal expectations, because nothing from the past can convincingly indicate the possibility of its appearance;

produces an extreme ,impact”;

despite the status of extreme event, human nature leads us to look for logical explanations necessary for its justification only after its occurrence, making the event to seem predictable and explicable to a very large extent.

\section{STUDY}

It is difficult for organizations to be connected to specific details when they should focus on generalities, issues as a whole, management strategies, and achieving goals. The focus is concentrated on the goals already set and countless times they fail to consider what they don't know. Therefore, they are not able to really estimate the opportunities, too vulnerable to the desire to simplify, implement and classify and are not open enough to reward those who can imagine the ,impossible”.

The life of an organization also benefits from periods of threats, volatility and turmoil. What Taleb has identified and calls ,,antifragile" is that category of things that not only gain from chaos, but need it to survive and flourish. The resilient resists shocks and remains the same; the anti-fragile is getting better and better. What is crucial is that the anti-fragile loves mistakes, because they cause small harms and big benefits from them. By adapting management strategies, company policies, planning, identifying opportunities, resources in an applied and erudite style, the results can exceed expectations (Hințea, C., Mora, Cristina, 2003).

In the midst of the COVID-19 crisis, but with the hope of returning to a life as close to normal as possible, managers should be focused on a number of key issues, but also on a number of measures they can take not only to react to the shock of the pandemic the organization is facing, but also to reshape the activity of their company and create a recovery plan.

Institutions and organizations need to be adaptable, predictable and proactive in making decisions to maintain business continuity and build business resilience.

The extreme impact of the COVID-19 pandemic, a rare and unpredictable event, is felt both psychologically individually and collectively, and financially, behaviorally, economically and socially. Managers are put in a position to adapt their management strategies in the current context, in an insecure world, with many variables that can change independently of their will, with a volatile and uncertain context, with new and unforeseen situations.

This unexpected event with major consequences and impact, collective and large-scale, requires the adaptation of management strategies.

The present study refers to the identification of priorities for managers in several small companies in Romania, in the current context. All of them have trade as their main activity, they have 
a small turnover, leading us to the so-called family business. The analyzed period is between September 2020 and January 2021, a period influenced by certain factors, such as: Romania was on ,alert” throughout all the country, there were certain restrictions, schools were held online, there were holidays winter, parliamentary elections that took place, it was the cold season too and the vaccination campaign began on December 26, 2020. The 10 companies analyzed in this study were severely affected by the pandemic and the measures imposed by the Romanian authorities. Sales decreased significantly, human resource problems increased, distribution problems and goods reception increased. The 10 ,employers" who actually participated in our study answered 20 questions in a questionnaire. The questionnaire was applied directly, for a better collection and interpretation of data. The results are formulated below and may be the basis for further research.

Thus, if before the pandemic the priorities of an organization were multiple, now the number one priority is represented by the healthy status and safety of people and their continued involvement in their duties, retention to work. The field of activity does not involve teleworking and, in the current context, it becomes even more difficult to select, recruit and hire the right person.

Ensuring the safety of employees at work has become essential. People expect concrete guidance and action from their employer, community members and political decision-makers. The chosen manner influences the long-term involvement of employees and ensures or not the continuity of the business. Workplace safety is an important item for the employee. 10 of the 10 participants answered that this is the main priority: the safety and health of themselves and their employees.

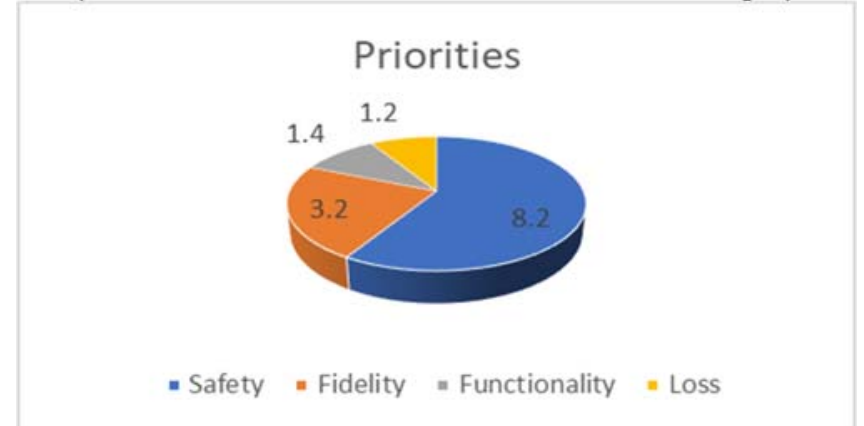

Figure 1. Priorities of the companies involved in the study, in the analyzed period

Source: author, based on own research

Identifying ways to rebuild a normal work environment by minimizing disruption to the organization involves a very fine balance and was a real challenge for all employers interviewed. Where teleworking or flexible working is not possible, as in the present case, and companies must bring employees to headquarters or in direct contact with customers, it is important to provide protection measures against infection or the spread of the disease. The budget must also be rethought to include these materials and safeguards. Even with the help of these measures, however, there were businesses that faced labour disruptions. Lack of labour and high costs caused by mobility restrictions imposed by various state and local government authorities have affected business. $50 \%$ of the analyzed local businesses have interrupted or stopped their activity at least once for a period of at least 5 days (Basnayake, H., 2020). It should also be borne in mind that the state has introduced tax incentives and assistance programs for small businesses and for industries such as tourism and hospitality, Horeca which have been severely affected but not for all areas of activity. In addition, in 8 of the companies, there were cases of requests for days off for personal reasons related to the pandemic (illness of employees, their death or the death of family members).

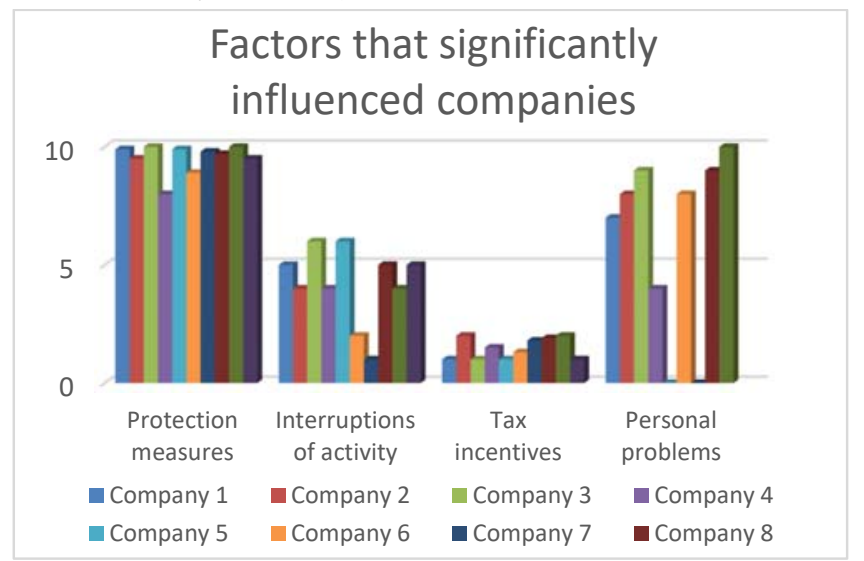

Figure 2. Priorities of the companies involved in the study, in the analyzed period

Source: author, based on own research

All employers that had participated in this study are looking for solutions to reshape the strategy for business continuity. All the analyzed companies faced important interruptions of their usual operations and poor performance during the COVID-19 crisis. At the beginning of this crisis, supply chain issues were important for companies with external exposure. Important changes in customer demand and behavior were also mentioned in the responses received, with repercussions on the business segments.

Employers have tried to assess their liquidity in the short term, $100 \%$ of them identifying that they have the minimum financial resources so necessary for survival. Even though they are in the field of consumption, the reductions in revenues were fully felt. Also, the shortening or modification of the operating program led to a decrease in revenues. Companies need to introduce a self-discipline for short-term cash flow monitoring that allows them to prevent pressures on cash flows and intervene at the right time. It must also maintain strict working capital discipline, in particular as regards the collection of claims and the management of stocks. In addition, creativity and proactive intervention are important to ease the working capital cycle. Throughout the crisis, companies need to stay in close contact with suppliers to identify any potential risks.

Another aspect identified was the monitoring of direct cost increases, including price increases, and their impact on overall product margins, to intervene where necessary through direct measures, tailored to specific needs and particularities.

Employers have identified the need to measure financial plans under stress in several scenarios in order to understand the potential impact on financial performance and to assess its duration. If the impact is significant and the previous budget assumptions and business plans are no longer relevant, they need to revise them in order to remain reliable. When their activity was significantly affected, employers took into account minimum operational requirements, including essential dependencies on labour, suppliers, location, rent and other costs or aspects.

Another relevant aspect of this study is the increasing importance of communication with relevant stakeholders. Clear, transparent and timely communication is needed in this context and to ensure support from employees, customers, customers, creditors, investors and authorities. These proactive actions help to mitigate the damage and identify the necessary measures, given that the overall situation is considered to be very volatile, 
with changes having potential for sudden and uncontrolled. The communication plan must try to find the balance between precaution and maintaining a positive mentality of usual activity.

The interpretation of the results also showed that resilience must be substantiated in preparation for the new normalcy. Once employers have solidified their strategies on the basis of new conditions that have emerged and been correctly identified, and after communicating the new direction to stakeholders, they need to implement these strategies on the basis of revised measures, continuing to monitor the situation, which will continue to changes frequently. Employers must identify any significant deviations from the plan in a timely manner so that the businesses they run avoid a subsequent negative impact.

Once the outbreak of COVID-19 is controlled, including through the ongoing national vaccination campaign, employers need to review and update their own business management strategies. They also need to assess how existing business continuity plans work. If there are deficiencies, employers must identify the root causes, which may be related to the timing of the measures, labour issues or issues outside the business. Increasing resilience and preparing optimized responses will lead to a better response to future crises.

All respondents stated that it was impossible to predict this COVID-19 crisis, using the conventional reasoning and forecasting tools used. All this time, from the beginning of the pandemic until now, companies must make own decisions and take active measures, keeping in mind the recovery, maintenance and, why not, development (Tudorescu, N., 2020). Once the crisis is over, it will be clear which companies have the resilience and agility to reshape their business strategy to be successful in the future and which do not. From the point of view of longer-term strategies, companies need to analyze how robust their business, management team, measures and initiatives taken during the crisis were.

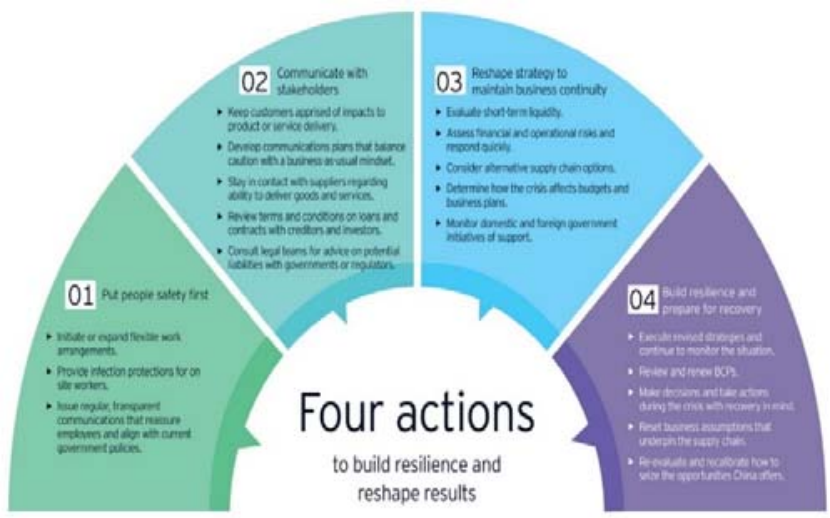

Figure 3. Priorities of the companies involved in the study, in the analyzed period

Source: https://www.ey.com/ro_ro/strategytransactions/companies-can-reshape-results-and-plan-forcovid-19-recovery

\section{CONCLUSIONS}

Rare and unlikely events happen more often than we think. Managers' thinking is limited and they make assumptions based on what they see, know and assume. The reality is much more complex and unpredictable than we think. At the same time, the assumptions relevant to normal situations are irrelevant to abnormal situations, especially when ,the rules of the game change radically". Extreme events take place and have extreme effects because they are new and completely unexpected.
Why are people or organizations surprised or find it difficult to recognize the rare and the new? Because they are used to extending current knowledge and experiences (know-how) to future events and experiences. At the same time, most of the education and experience gained, both formal and otherwise, is based on historical knowledge that has been offered "induced" by others. The most effective for organizations would be to find a balance between known and unknown and between the limits of knowledge and experience already gained. The occurrence of unexpected events is necessary to find this balance. In this way, the rare and the unexpected are much more significant for the formation of knowledge, and the adaptability and speed of decisions and their implementation are essential in the survival of organizations.

\section{REFERENCES}

1. Basnayake, H., et. al. (2020) How companies can reshape results and plan for a COVID-19 recovery, Ernst \& Young Global Limited, ey.com.

2. Hințea, C.; Mora, Cristina (2003) Management strategic în administrația publică. Revista Transilvană de Științe Administrative, IX, 25-33.

3. Montanari, J.; Daneke, G.; Bracker, J. (1989) Strategic Management for the Public Sector: Lessons from the Evolution of Private- Sector Planning, published in J. Rabin, G.J. Miller si W.B. Hildreth(eds) Handbook of Strategic Management, Marcel Dekker, New York si Base.

4. Taleb, N. (2010) The Black Swan: Second Edition: The Impact of the Highly Improbable: With a new section: „On Robustness and Fragility", Paperback.

5. Taleb, N. (2016) Incerto: Fooled by Randomness, The Black Swan, The Bed of Procrustes, Antifragile Paperback.

6. Tudorescu, N. (2020) Managementul instituțiilor publice, Note de curs.

7. https://www.descopera.org/teoria-lebedei-negre/, last accessed 02/20/2021.

8. Juvenal, Satires, VI, (165).

9. https://www.ey.com/ro_ro/strategytransactions/companies-can-reshape-results-and-plan-forcovid-19-recovery, last accessed 02/20/2021. 